ISSN 0103-8478

\title{
Forma nervosa da artrite-encefalite caprina
}

\author{
Nervous form of caprine arthritis-encephalitis
}

\begin{abstract}
Karla Moraes Rocha Guedes ${ }^{\mathrm{I}}$ Vanessa da Silva MustafaII Pedro Miguel Ocampos Pedroso ${ }^{\mathrm{III}}$

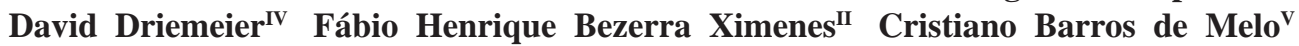
José Renato Junqueira Borges ${ }^{\mathrm{II}}$ Márcio Botelho de Castro ${ }^{\mathrm{II}}$
\end{abstract}

\begin{abstract}
São descritos dois casos de caprinos, fêmeas, RESUMO mestiços da raça Saanen de dois meses de idade com sinais clínicos de paresia de membros posteriores, incoordenação, dificuldade respiratória e caquexia, que foram submetidos à eutanásia, devido ao prognóstico desfavorável. Na necropsia, observouse congestão do sistema nervoso central (SNC) e consolidação pulmonar nos dois caprinos. Microscopicamente, as alterações foram caracterizadas por leucoencefalomielite linfoplasmocítica multifocal, com vacuolização do neurópilo e esferoides axonais, leptomeningite, pneumonia intersticial não supurativa no caprino A e broncopneumonia bacteriana no caprino B. O exame de imunohistoquímica (IHQ) foi positivo para o vírus da artrite-encefalite caprina em fragmento de tálamo. A prova de imunodifusão em gel de ágar (IDGA) foi realizada em vinte animais do rebanho de origem e dezesseis animais foram positivos. $O$ diagnóstico da forma nervosa da infecção pelo vírus da artrite-encefalite caprina (CAEV) foi baseado no quadro clínico-patológico, IHQ e IDGA. Esta apresentação clínica da CAE pode ser pouco comum no Brasil, mas deve ser considerada em caso de doenças neurológicas em pequenos ruminantes.
\end{abstract}

Palavras-chave: doença neurológica, lentivírus de pequenos ruminantes, leucoencefalomielite.

\section{ABSTRACT}

Two cases are described of female goats, Saanen crossbreds, two months old, with clinical signs of hind limb paresis, incoordination, difficulty breathing and cachexia, which were subjected to euthanasia due to unfavorable prognosis. At necropsy it was possible to observe that there was congestion of the central nervous system (CNS) and pulmonary consolidation in both goats. Microscopic changes were characterized by multifocal lymphoplasmacytic leucoencephalomielitis, with vacuolization of neuropile and axonal spheroids, leptomeningitis, interstitial nonsupurative pneumonia in goat $A$ and bacterial bronchopneumonia in goat B. Immunohistochemistry (IHC) was positive for the caprine arthritis - encephalitis virus in thalamus fragments. The agar gel immunodiffusion (AGID) test was performed in sera sample of twenty animals and sixteen resulted positive. Diagnosis of the nervous form of caprine arthritisencephalitis virus (CAEV) infection was based on clinical and pathological status, IHC and AGID. This clinical presentation of CAE could be uncommon in Brazil, but must be considered in case of neurologic diseases in small ruminants.

Key words: neurologic disease, small ruminant lentiviruses, leucoencephalomyelitis.

O vírus da artrite-encefalite caprina (CAEV), pertencente à família Retroviridae, juntamente com o vírus maedi-visna(MVV) compõem o grupo dos lentivírus dos pequenos ruminantes. Eles são assim classificados por possuírem várias similaridades, como morfologia e interação com o hospedeiro, podendo ocorrer infecção entre espécies (CALLADO et al., 2001). Ambos têm tropismo por células do sistema monocítico-macrofágico, mas partículas virais podem ser encontradas em células

IFaculdade de Medicina Veterinária, Universidade de Cuiabá (UNIC), Av. Manoel José de Arruda, n. 3100, 78065-900, Cuiabá, MT, Brasil.

E-mail: kmrgkarla@yahoo.com.br. Autor para correspondência.

IH Hospital Veterinário, Universidade de Brasília (UnB), Brasília, DF, Brasil.

III Laboratório de Patologia Veterinária, Centro de Ciências Agrárias, Ambientais e Biológicas (CCAAB), Universidade Federal do Recôncavo da Bahia (UFRB), Cruz das Almas, BA, Brasil.

${ }^{\text {IV }}$ Setor de Patologia Veterinária (SPV), Departamento de Patologia Clínica Veterinária, Faculdade de Veterinária (FAVET), Universidade Federal do Rio Grande do Sul (UFRGS), Porto Alegre, RS, Brasil.

VLaboratório de Doenças Infecciosas de Notificação Obrigatória (DINO), Faculdade de Agronomia e Medicina Veterinária (FAV), UnB, Brasília, DF, Brasil. 
do epitélio tubular renal e do epitélio intestinal e mamário (ZINK et al., 1990; BLACKLAWS et al., 2004). O vírus da CAE pode provocar, em animais jovens, de dois a quatro meses de idade, quadro de meningoencefalomielite linfoplasmocítica, principalmente na substância branca ao redor do epêndima e nos funículos laterais da medula espinhal, enquanto, em animais adultos, está envolvido com o surgimento de artrite crônica e mastite (ZINK et al., 1990; CALLADO et al., 2001; MOOJEN \& RIETCORREA, 2007; MACLACHLAN \& DUBOVI, 2011). Nas três formas clínicas (neurológica, articulare mamária) pode ocorrer também quadro de pneumonia não supurativa e infecção bacteriana secundária, provavelmente devido ao comprometimento do sistema imune celular (CALLADO et al., 2001). $\mathrm{Na}$ forma nervosa da doença, o quadro clínico é caracterizado por ataxia, paresia e paralisia de membros pélvicos e torácicos, mas alterações macroscópicas no sistema nervoso central (SNC) são pouco significativas (ZINK et al., 1990; CALLADO et al., 2001). O objetivo deste trabalho é relatar dois casos da forma nervosa da artrite-encefalite caprina, uma vez que essa doença é pouco comum no país e os relatos científicos são escassos.

No mês de julho de 2007, foram atendidos, no Hospital Veterinário da Universidade de Brasília (HVet/UnB), dois caprinos (A e B), fêmeas, mestiças da raça Saanen, com 60 dias de idade, que apresentavam quadro clínico de fraqueza dos membros pélvicos, quedas, decúbito esternal, paresia flácida de membros pélvicos, taquipneia com ruído traqueal intenso, desidratação, perda gradativa de propriocepção dos membros pélvicos, diminuição do reflexo pupilar, movimentos mastigatórios, tremores de cabeça e posterior decúbito lateral. O caprino B apresentava midríase. Devido ao prognóstico desfavorável, os animais foram submetidos à eutanásia, seguindo as recomendações da resolução $n^{-}{ }^{0} 714$ do Conselho Federal de Medicina Veterinária (CFMV, 2002).

A propriedade de origem dos caprinos, localizada na região administrativa de São Sebastião, Distrito Federal, foi inspecionada e foi colhido sangue de vinte fêmeas jovens e adultas de um rebanho de setenta animais, para realização do exame de imunodifusão em ágar gel (IDGA) (ABREU et al., 1998) no Laboratório de Doenças Infecciosas de Notificação Obrigatória na Universidade de Brasília (DINO/UnB). Dos vinte animais testados, dezesseis resultaram positivo para infecção pelo $\mathrm{CAEV}$, com ocorrência de anticorpos de $80 \%$.

Na necropsia do caprino A, observaramse áreas multifocais de consolidação nos lobos diafragmáticos dos pulmões. No SNC, havia congestão discreta nas leptomeninges. Caquexia foi um achado do caprino B, além de áreas multifocais de consolidação pulmonar.

Microscopicamente, os achados foram de leptomeningite linfoplasmocítica discreta e multifocal e encefalite linfoplasmocítica discreta a moderada em várias áreas do encéfalo, tronco encefálico e medula espinhal. Nos hemisférios cerebrais, os focos de infiltrado inflamatório foram observados na substância cinzenta e principalmente na substância branca adjacente ao epêndima, quando se viam também manguitos perivasculares de linfócitos e plasmócitos (Figura 1 A). No tronco encefálico, havia áreas multifocais e discretas de necrose neuronal, vacuolização, esferoides axonais e infiltrado inflamatório linfoplasmocítico e histiocítico no neurópilo e ao redor de vasos. Lesão semelhante era observada na substância branca da zona medular do cerebelo dos dois animais e nos funículos dorsais, laterais e ventrais da medula espinhal cervical do caprino A. Na medula torácica e lombar, foi observado infiltrado linfoplasmocítico perivascular nos cornos dorsais e funículos dorsais e laterais. No caprino B, as lesões eram semelhantes, mas havia ainda infiltrado linfoplasmocítico moderado no plexo vascular do ventrículo lateral (Figura $1 \mathrm{~B}$ ), e quantidade moderada de células gitter nas regiões de infiltrado adjacente ao epêndima.

Nos pulmões dos dois caprinos, havia focos de infiltrado linfoplasmocítico na parede dos alvéolos e macrófagos na luz dos alvéolos (Figura 1 C). No caprino B, havia ainda focos de infiltrado neutrofílico no interstício, luz de bronquíolos e alvéolos, com colônias bacterianas intralesionais.

Cortes histológicos da região talâmica dos dois caprinos foram enviados ao Setor de Patologia Veterinária da Universidade Federal do Rio Grande do Sul (SPV/UFRGS) e submetidos à técnica de imunohistoquímica (IHQ) para o vírus da artrite-encefalite caprina. A recuperação antigênica foi feita em solução de tampão citrato $10 \mathrm{mM}(\mathrm{pH} \mathrm{6,0)}$ por 15 minutos a uma temperatura de $100^{\circ} \mathrm{C}$. Foi utilizado o anticorpo primário monoclonal (CAE P13B1/VMRD) na diluição de 1:100, overnight. Em seguida, foram tratados com anticorpo secundário biotinalado contra imunoglobulina de coelho, camundongo e cabra por 20 minutos e depois com conjugado streptavidina-peroxidase por mais 20 minutos (LSAB ${ }^{\circledR}+$ KIT, Dako Corporation, Carpinteria, Califórnia, EUA). Como cromógeno, foi utilizado o 3,5-diamino-benzidina (DAB). O exame detectou imunomarcação positiva para o CAEV em amostras dos dois animais, com presença de antígenos no citoplasma 


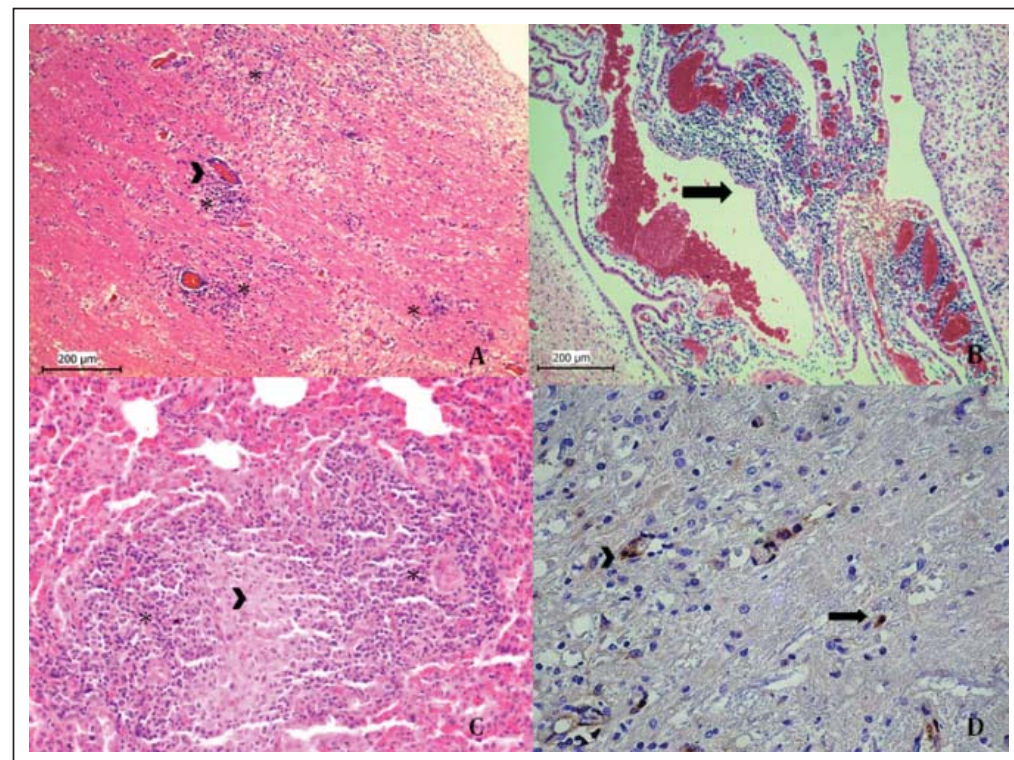

Figura 1 - A) Caprino A. SNC. Substância branca adjacente ao epêndima. Áreas multifocais de infiltrado linfoplasmocítico moderado no neurópilo (asterisco) e ao redor de vasos (cabeça de seta) e congestão moderada de vasos. H\&E. Obj.20x; B) Caprino B. SNC. Ventrículo lateral. Infiltrado inflamatório linfoplasmocítico acentuado no plexo vascular (seta) e congestão de vasos. H\&E. Obj. 20x; C) Caprino A. Pulmão. Infiltrado linfoplasmocítico moderado na parede dos alvéolos (asterisco), infiltrado histiocítico discreto na luz dos alvéolos (cabeça de seta) e congestão dos capilares alveolares. H\&E. Obj. 40x; D) Caprino A. Tálamo. Imunomarcação positiva para proteína do vírus da CAE em células endoteliais (cabeça de seta) e oligodendrócitos (seta). Imuno-histoquímica pelo método biotinaestreptavidina-peroxidase e contra-corada com hematoxilina. Obj.40x.

de células endoteliais e oligodendrócitos em meio à substância branca (Figura 1 D).

Foram acometidos caprinos com menos de seis meses de idade, como citado na literatura (WILKIE, 1980; CALLADO et al., 2001), e os sinais clínicos de paresia progressiva de membros pélvicos e incoordenação foram semelhantes ao que normalmente é observado nos casos de CAE na forma nervosa (WILKIE, 1980), com exceção da midríase, que normalmente não é descrita. Lesões de artrite ou mastite não estavam presentes.

As lesões microscópicas observadas no SNC, como leucomeningoencefalite não supurativa, necrose da substância branca, desmielinização de fibras nervosas e infiltrado inflamatório de linfócitos, plasmócitos e macrófagos no pulmão, são condizentes com os achados de caprinos naturalmente infectados pelo vírus da CAE (ZINK et al., 1990; STORSET et al., 1997) e, provavelmente, explicam o quadro de incoordenação e paresia de membros pélvicos observados nos dois animais.

A imunomarcação em células endoteliais e oligodendrócitos nas áreas de infiltrado inflamatório no tálamo dos dois caprinos infectados é considerada uma forma importante de diagnóstico da infecção pelo vírus da CAE (STORSET et al., 1997). Esse resultado permite descartar a possibilidade de infecção cruzada com o vírus de Maedi-Visna dos ovinos (MACLACHLAN \& DUBOVI, 2011).

Foi detectada ocorrência de $80 \%$ de anticorpos para o vírus da CAE na amostragem dos animais do rebanho de origem. Esse número é alto, quando comparado com outros estudos anteriores que apresentaram baixos níveis da infecção pelo CAEV no Brasil, como de 33\% em São Paulo (LARA et al., 2002) e 2,50\% no Piauí (BATISTA et al., 2004).

Portando, o diagnóstico de artriteencefalite caprina na sua forma nervosa foi baseado nos dados clínico-patológicos, imuno-histoquímicos e sorológicos do rebanho. Essa apresentação clínica da CAE pode ser pouco comum no Brasil, mas deve ser considerada no diagnóstico de casos de doenças neurológicas em pequenos ruminantes.

\section{AGRADECIMENTOS}

Agradecimento especial ao Conselho Nacional de Pesquisa e Desenvolvimento (CNPq) através do processo $\mathrm{CNPq}$ 578435/2008-0, pelo suporte financeiro. 


\section{REFERÊNCIAS}

ABREU, S.R.O. et al. Produção de antígeno nucleoprotéico do vírus da artrite-encefalite caprina e comparação com o do vírus maedi-visna para utilização em teste de imunodifusão em ágar gel. Pesquisa Veterinária Brasileira, v.18, p.57-60, 1998.

BATISTA, M.C.S. et al. Anticorpos anti-lentivirus de pequenos ruminantes em caprinos integrantes de nove municípios piauienses. Ciência Veterinária nos Trópicos, v.7, n.2/3, p.75-81, 2004.

BLACKLAWS, B.A. et al. Transmission of small ruminant lentiviruses. Veterinary Microbiology, v.101, p.199-208, 2004. Disponível em: <http://www.sciencedirect.com/science/ article/pii/S0378113504001555>. Acesso em: 20 set. 2012. doi: S0378113504001555.

CALLADO, A.K.C. et al. Lentivírus de pequenos ruminantes (CAE e Maedi-Visna): revisão e perspectivas. Pesquisa Veterinária Brasileira, v.21, n.3, p.87-97, 2001. Disponível em: $<$ http://www.scielo.br/scielo.php?script=sci_arttext\&pid=S0100736X2001000300001>. Acesso em: 19 set. 2012. doi: 10.1590/ S0100-736X200100030000.

CFMV(CONSELHO FEDERAL DE MEDICINA VETERINÁRIA DO BRASIL). Resolução n.714, de 20 de junho de 2002. Procedimentos e métodos de eutanásia em animais. Brasília, 2002. 6p.
LARA, M.C.C.S.H. et al. Identificação imuno-sorológica de anticorpos anti-vírus da artrite-encefalite dos caprinos: comparação das técnicas de imunodifusão em gel de ágar, ensaio imunoenzimático e imunofluorescência indireta. Arquivos do Instituto Biológico, v.69, n.4, p.1-5, 2002. Disponível em: <http:// www.biologico.sp.gov.br/docs/arq/V69_4/lara.pdf>. Acesso em: 19 set. 2012. doi: docs/arq/V69_4/lara.

MACLACHLAN, N.J.; DUBOVI, E.J. Fenner's veterinary virology. 4.ed. London: Academics, 2011. 507p.

MOOJEN, V.; RIET-CORREA, F. Artrite-encefalite caprina. In: RIET-CORREA, F.; SCHILD, A. L.; LEMOS, R. A. A.; BORGES, J. R. J. Doenças de ruminantes e equídeos. 3.ed. Santa Maria: Pallotti, 2007. V.1, p. 72-80.

STORSET, A K. et al. Immunohistochemical identification of caprine arthritis-encephalitis virus in paraffin-embedded specimens from naturally infected goats. Veterinary Pathology, v.34, p.180-188, 1997. Disponível em: <http://vet.sagepub. com/content/34/3/180.short>. Acesso em: 19 set. 2012 . doi: 10.1177/030098589703400302.

WILKIE, I.W. Leukomyelitis in the goat: a report of three cases. Canadian Veterinary Journal, v.21, p.203-205, 1980.

ZINK, M.C. et al. Pathogenesis of caprine arthritis encephalitis virus-Cellular localization of viral transcripts in tissues of infected goats. American Journal of Pathology, v.136, n.4, p.843-854, 1990. 